infections. Freckling of the trunk was conspicuous. Jejunal biopsy showed partial villus atrophy. Hypothyroidism was diagnosed at three and a half years of age and development was normal.

Zadic et $a l^{4}$ reported a girl who had hypothyroidism and sparse hair. In addition this patient also had facial dysmorphism (hypertelorism, depressed nasal bridge, and small mandible), oligodontia of both primary and secondary teeth, hypohidrosis, and an epibulbar dermoid cyst.

Patients with Johanson-Blizzard syndrome ${ }^{5}$ may have sparse hair and congenital hypothyroidism. These cases also have many other features, the most consistent of which are hypoplastic nasal alae, congenital cutis aplasia scalp defects, aplasia of the teeth, pancreatic exocrine deficiency, and sensorineural deafness.

Our cases differ from the previously reported cases of abnormal hair and hypothyroidism because they did not have failure to thrive or recurrent chest infections. Sweating and sweat pore counts were normal and significant facial dysmorphism was not a feature. The ultrastructural hair abnormalities were different from those described by Pabst et al $l^{2}$ (loss of scaling pattern and pili torti in addition to reduced fibre diameter). Upper airway anomalies in conjunction with congenital hypothyroidism has not been previously described. Hypothyroidism in our cases is probably the result of congenital athyroidia. It seems unlikely that this was the cause in other patients in view of the later presentation and normal mental development.
It is likely that this syndrome is genetically determined. The mode of inheritance is uncertain, but $\mathrm{X}$ linked recessive transmission with partial expression in the mother (in view of unilateral choanal atresia) and autosomal recessive inheritance must be considered.

These children were ascertained through a regional congenital hypothyroid screening programme, emphasising the importance of being aware of phenotypic as well as biochemical abnormalities. Further cases of this syndrome should be easier to ascertain through a hypothyroid screening programme.

\footnotetext{
References

1 Verbov J. Palmar ridge appearances in normal newborn infants and ridge appearance in relation to eccrine sweating. $\mathrm{Br} J$ Dermatol 1975;93:645-8.

2 Pabst HF, Garth O, McCoy EE. Hypohidrotic ectodermal dysplasia with hypothyroidism. J Pediatr 1981;98:223-7.

${ }^{3}$ Pike MG, Baraitser M, Dinwidie R, Atherton DJ. A distinctive type of hypohydrotic dysplasia featuring hypothyroidism. $J$ Pediatr 1986;108:109-11.

${ }^{4}$ Zadic Z, Barak Y, Levin S. Case report 112. Syndrome Identification 1983;(C4):24-7.

5 Johanson A, Blizzard R. A syndrome of congenital aplasia of the alae nasi, deafness, hypothyroidism, dwarfism, absent permanent teeth and malabsorption. J Pediatr 1971;79:982-7.
}

Correspondence and requests for reprints to $\mathrm{Dr} J \mathrm{~S}$ Bamforth, Department of Clinical Genetics, University of British Columbia, 4490 Oak Street, Vancouver, BC V6H 3V5, Canada.

\title{
Hydrocephalus, tall stature, joint laxity, and kyphoscoliosis: a new inherited disorder of connective tissue?
}

\author{
PETER DAISH*, MARTIN J HARDMAN*, AND MARGARET A LAMONT ${ }^{*}$ \\ ${ }^{*}$ Department of Paediatrics, St Mary's Hospital, Portsmouth; and †Department of Child Health, \\ Southampton General Hospital, Southampton.
}

SUMMARY We describe two sisters with hydrocephalus, tall stature, joint laxity, and thoracolumbar kyphosis.

\section{Case reports}

These two girls are the only children of healthy, unrelated, professionally qualified parents. The

Received for publication 2 Sepember 1987.

Revised version accepted for publication 7 March 1988 father, aged 34 years, is $185 \mathrm{~cm}$ tall $(+1 \cdot 6 \mathrm{SD})$. The mother, aged 30 years, is $162 \mathrm{~cm}$ in height (mean). Their head circumferences are within the normal ranges at $58 \mathrm{~cm}(+1.8 \mathrm{SD})$ and $56.5 \mathrm{~cm}(+1.5 \mathrm{SD})$ respectively.

The father was found on a routine medical examination at the age of 21 to have an aortic regurgitant murmur. He has remained asymptomatic and at present has no clinical signs. Recent cardiac ultrasound studies with Doppler colour flow mapping showed normal aortic root dimensions, 
mild floppiness of the aortic valve leaflets, and minimal aortic regurgitation.

The mother has moderately increased joint mobility: she is able to rest the palms of her hands on the floor on forward flexion of her trunk and can hyperextend her elbows and knees, but not beyond $10^{\circ}$. The little finger of her non-dominant hand can be dorsiflexed passively to $75^{\circ}$ with the forearm flat. However, her thumbs cannot be passively apposed to the flexor aspect of her forearms. She does not bruise or bleed excessively and surgical wounds heal normally. Cardiac ultrasound examination is unremarkable.

Apart from the mother's increased joint mobility both parents appear entirely normal on clinical examination.

Their first child was born normally at 40 weeks' gestation after a pregnancy complicated by mild hypertension in the last three weeks. Birth weight was $3340 \mathrm{~g}$ (mean), length $53 \mathrm{~cm}(+1 \cdot 3 \mathrm{SD})$, and head circumference $34.5 \mathrm{~cm}(-0.3 \mathrm{SD})$.

On initial neonatal examination she was noted to have a large anterior fontanelle, wide cranial sutures, and a prominent lumbar spine. She also had a right Erb's palsy, but in all other respects appeared normal.

Her head circumference increased rapidly and at three weeks of age she had clinical evidence of hydrocephalus with a large head (circumference $38.0 \mathrm{~cm},+1.6 \mathrm{SD})$, parietal bossing, and a full anterior fontanelle.

Cranial ultrasound showed that both lateral ventricles were moderately dilated, the right more than the left. Ventricle-hemisphere ratios were 0.70 and 0.65 respectively. A right ventriculoatrial shunt with a low pressure valve was inserted and subsequent head growth was within normal limits. CT scan at nine months confirmed relief of the hydrocephalus. When the distal catheter was lengthened routinely at 16 months it was felt that the valve was no longer functioning.

The right Erb's palsy recovered slowly but at three months it was noted that she tended to keep her left hand fisted with the thumb firmly adducted across the palm.

At four months of age she was found to have developed a moderate thoracolumbar kyphosis. This became progressively more marked and at nine months $x$ rays showed a kyphosis of $55^{\circ}$ and a scoliosis of $25^{\circ}$ convex to the right between $\mathrm{T} 2$ and L3. At 13 months she was placed in a plaster cast jacket for two months and then a brace until 20 months. The angulation of the spine gradually diminished and at two years she had only minimal kyphosis.

Excessive laxity of all joints became clinically obvious at five months. When she was seven months $\Rightarrow$ old she sustained an anterior dislocation of the right? shoulder while being dressed. The arm was easily? relocated but over the next three years she experienced recurrent dislocation of both shoulders.

During the neonatal period she developed an $\mathbb{D}_{0}^{\mathbb{D}}$ umbilical hernia which gradually enlarged; when this was repaired at 16 months the defect measured $2 \stackrel{\text { s }}{2}$ $\mathrm{cm}$ by $2 \mathrm{~cm}$.

Her length at the age of seven months was $73 \cdot 1 \mathrm{~cm} \overrightarrow{\vec{\omega}}$ (+3.1 SD) and she has maintained this unexpectedly increased linear growth.

She is now four years old and is a tall, thin, delicate girl with slender limbs, long fingers, ando mobile joints (fig 1). Height is $112 \mathrm{~cm}(+2.7 \mathrm{SD}), \overrightarrow{\mathrm{G}}$ weight $14.2 \mathrm{~kg}(-0.7 \mathrm{SD})$, and head circumference $47.0 \mathrm{~cm}(-1.9 \mathrm{SD})$. She exhibits general diminution? in strength and is unable to lift up her forearmsexcept by shoulder abduction. Right hand functiona is normal but she has a palmar grasp on the left with? poor release. She walks with a knock kneed gait产 sliding her feet along the ground. Ophthalmological examination shows no evidence of lens subluxation. Intellectual development is within normal limits.

Her bone age at three years was between three? and three and a half years. Cardiac ultrasound examination at four years shows minor floppiness of

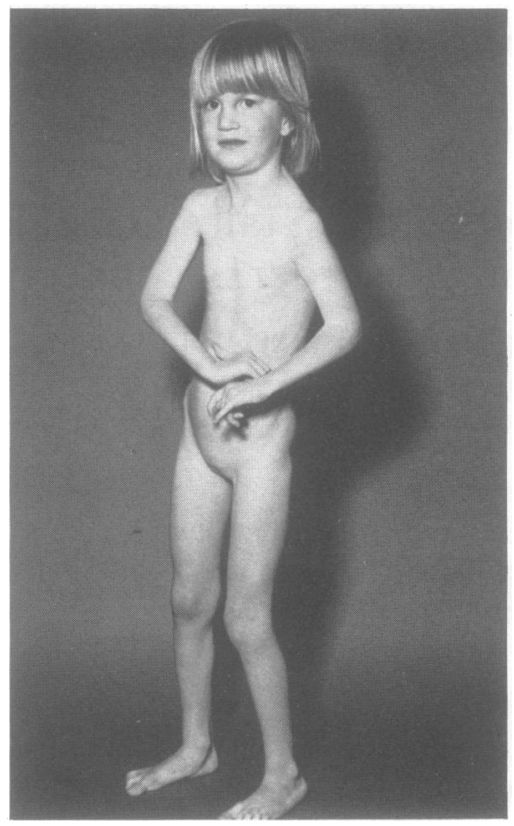

FIG 1 The older sister aged four years. 
the mitral valve with posterior bowing of both leaflets during systole. However, Doppler studies do not show any mitral regurgitation. She has normal aortic root dimensions.

The parents were told that this unusual combination of abnormalities was unlikely to recur and proceeded with a second pregnancy.

The second child was delivered by emergency caesarean section for fetal distress at 41 weeks four

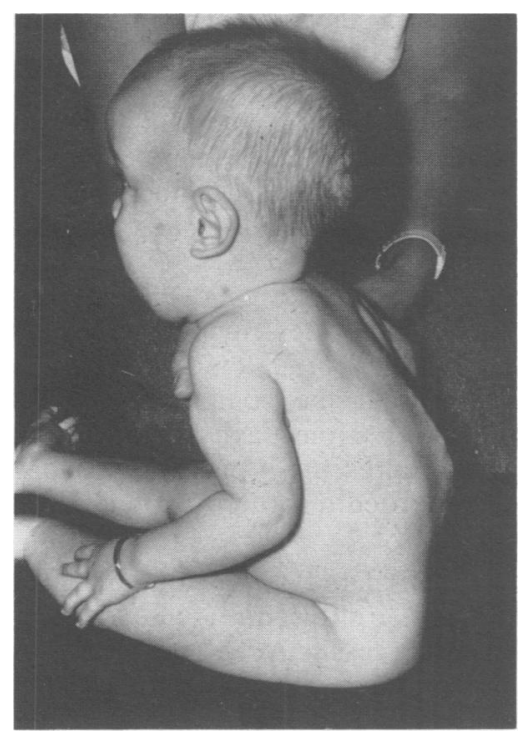

FIG 2 The younger sister aged five and a half months. days by dates after an uneventful pregnancy. Ultrasound scans at 18 and 23 weeks' gestation had shown the ventricle-hemisphere ratios to be within normal limits.

Birth weight was $3650 \mathrm{~g} \mathrm{(+0.4} \mathrm{SD),} \mathrm{length} 54 \mathrm{~cm}$ $(+2 \cdot 2 \mathrm{SD})$, and head circumference $36 \cdot 0 \mathrm{~cm}(+1 \cdot 0$ SD). The initial neonatal examination was unremarkable. She fed well from the breast and had regained her birth weight on discharge home at eight days.

She was referred at five and a half months to our Child Assessment Clinic because of increasing head size and concern over the appearance of her back. In addition, she had been noticed by her mother to have very lax joints.

She was an alert, well nourished, long infant with a large head, marked parietal and frontal bossing, and a full anterior fontanelle. She exhibited frequent sunsetting. Head circumference was $49.0 \mathrm{~cm}$ (+4.9 SD), length $74 \mathrm{~cm}(+3.6 \mathrm{SD})$, and weight 8.25 $\mathrm{kg}(+1.9 \mathrm{SD})$. She had soft skin, long slender fingers, flexible joints, and a high arched palate. The left thumb was held adducted across the palm and there were diminished spontaneous movements of the left arm and leg. Right hand function was normal but she had an ulnar approach to objects with the left hand. She had a marked thoracolumbar kyphosis (fig 2).

A CT scan showed hydrocephalus affecting all four ventricles. The pattern was symmetrical but there was relatively increased distension of the posterior half of the right ventricle (fig 3). A ventriculoperitoneal shunt was inserted.

She has maintained her linear growth and at 12
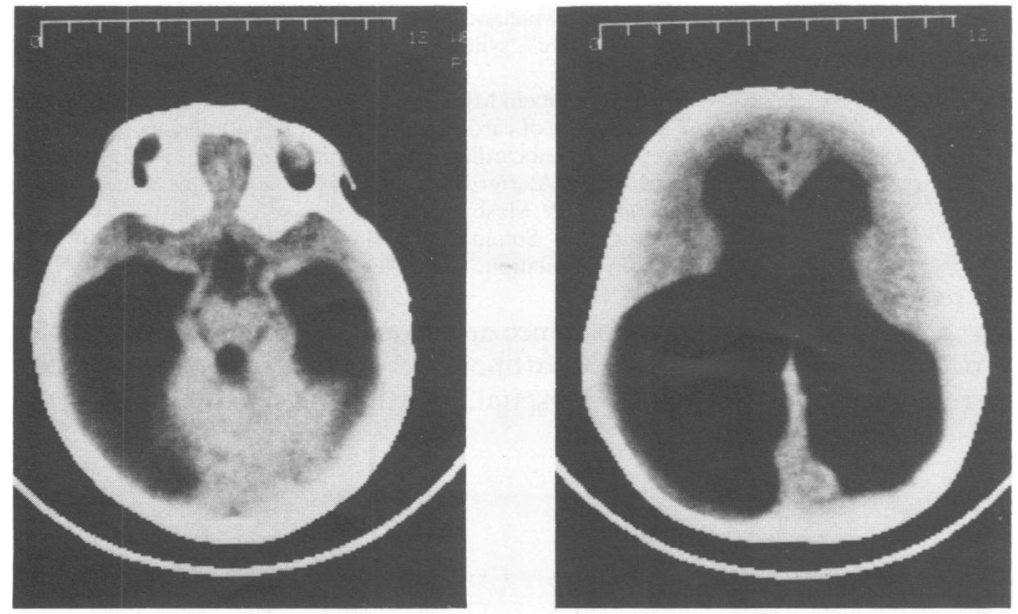

FIG 3 CT images of the younger sister aged five and a half months showing hydrocephalus with relatively increased distension of the posterior half of the right ventricle. 
months her length is $83.5 \mathrm{~cm}(+3.5 \mathrm{SD})$. Cardiac ultrasound and ophthalmological examinations have shown no abnormality.

The following investigations carried out on both girls have been normal: chromosome analysis, blood and urine amino acid chromatography, serum electrolytes, urea, creatinine, calcium, alkaline phosphatase, creatine kinase, $\mathrm{T} 4$, and urine screen for mucopolysaccharides.

\section{Discussion}

These children clearly have an inherited condition which can be loosely described as 'a disorder of connective tissue'. The mode of inheritance has important implications for the family and in particular for the two girls.

Their unusual constellation of abnormalities combined with the parents' ostensibly normal appearance provides strong evidence for recessive inheritance. However, it could be argued that the girls show variable expression of a dominantly inherited condition. Increased linear growth and kyphoscoliosis suggest the possibility of Marfan's syndrome and in this respect the father's aortic regurgitation due to mild floppiness of the valve leaflets may be significant. The 'floppy valve' syndrome (characterised by non-inflammatory myxoid degeneration of the valve leaflets) more commonly affects the mitral valve but aortic involvement is well recognised. ${ }^{1}$ Read et al, ${ }^{2}$ who first described the floppy valve syndrome, found that several close relatives of their patients had borderline stigmata of Marfan's syndrome although none was a florid example of the condition. Their conclusion that the floppy valve syndrome is a possible forme fruste of Marfan's syndrome has not, however, been corroborated by subsequent studies. ${ }^{34}$ With the wider availability of sophisticated, non-invasive techniques of cardiological investigation many more subjects with isolated floppy valve syndrome are being recognised in the general population ${ }^{1}$; whether the valve lesions in these subjects represent some generalised disorder, a non-specific response to a variety of factors, or a normal ageing change ${ }^{4}$ has yet to be fully elucidated.

The girls' condition bears a closer resemblance to Ehlers-Danlos syndrome in which kyphoscoliosis and umbilical herniae commonly occur ${ }^{5}$ and it is possible that the mother's joint hypermobility repre- sents a milder form of the syndrome. She has $\stackrel{+}{\rightleftarrows}$ however, no other associated features and achieves? only three out of nine on the articular mobility scoring system of Beighton et al. ${ }^{6}$

A further possibility is that these girls represen $\frac{\bar{s}}{5}$ genetic compounds having inherited abnormal con nective tissue genes from both parents. Collageren studies to date have not been feasible but might inthe future resolve these questions concerning the mode of inheritance.

The most striking and clinically significant feature of these two girls is the hydrocephalus which in each has been associated with relatively increased disten $\dot{i}$ sion of the right ventricle together with corre? sponding contralateral neurological deficits $\vec{i}$ Hydrocephalus occurs in a number of inherited disorders of connective tissue including achondro을 plasia, osteogenesis imperfecta congenita, and Larsen's syndrome and in these conditions may be్ secondary to the underlying skeletal disorder. Hydrocephalus is not described as being associate with either Marfan's or Ehlers-Danlos syndromes. $\vec{c}$

We suggest that the combination of hydroce $\infty$ phalus, tall stature, joint laxity, and kyphoscoliosis in these girls represents a previously undescribed recessively inherited disorder of connective tissue.

We wish to thank Drs B R Keeton and J Caplin fo performing cardiac ultrasound studies on the children? and their parents respectively, and $\mathrm{Mr} \mathrm{M} \mathrm{J}$ Absolono $\overrightarrow{\vec{b}}$ for carrying out the ophthalmological examinations. 3

\section{References}

1 Anonymous. Aortic valve disease today. Lancet 1985;ii:592-3 2 Read RC, Thal AP, Wendt VE. Symptomatic valvular myxomatous transformation (the floppy valve syndrome): a possible forme fruste of the Marfan syndrome. Circulation 1965;32:897 910.

${ }^{3}$ Frable WJ. Mucinous degeneration of the cardiac valves: the "floppy valve" syndrome. J Thorac Cardiovasc Surg 19690 58:62-70.

4 Rippe J, Fishbein MC, Carabello B, et al. Primary myxomatous degeneration of cardiac valves: clinical, pathological, haemodynamic and echocardiographic profile. Br Heart J 1980;44:621-9.

5 McKusick VA. Heritable disorders of connective tissue. 4th ed St Louis: C V Mosby, 1972.

6 Beighton PH, Solomon L, Soskolne CL. Articular mobility in an African population. Ann Rheum Dis 1973;32:413-8.

Correspondence and requests for reprints to Dr Petes Daish, Department of Paediatrics, Northamptor General Hospital, Northampton NN1 5BD. 